\title{
Evaluating the impact of environmental interventions across 2 countries: the International Bikeshare Impacts on Cycling and Collisions Study (IBICCS) Study protocol
}

Daniel Fuller ${ }^{1 *}$, Lise Gauvin ${ }^{2,3}$, Anne-Sophie Dubé ${ }^{2,3,4}$, Meghan Winters ${ }^{5}$, Kay Teschke ${ }^{6}$, Elizabeth T Russo ${ }^{7}$, Andi Camden ${ }^{8}$, Carol Mee ${ }^{8}$ and Steven Marc Friedman ${ }^{9,10}$

\begin{abstract}
Background: Few international studies examine public bicycle share programs (PBSP) health impacts. We describe the protocol for the International Bikeshare Impacts on Cycling and Collisions Study (IBICCS).

Methods: A quasi-experimental non-equivalent groups design was used. Intervention cities (Montreal, Toronto, Boston, New York and Vancouver) were matched to control cities (Chicago, Detroit, and Philadelphia) on total population, population density, cycling rates, and average yearly temperature. The study used three repeated, cross-sectional surveys in intervention and control cities in Fall 2012 (baseline), 2013 (year 1), and 2014 (year 2). A non-probabilistic online panel survey with a sampling frame of individuals residing in and around areas where PBSP are/would be implemented was used. A total of 12,000 respondents will be sampled. In each of the 8 cities 1000 respondents will be sampled with an additional 4000 respondents sampled based on the total population of the city. Survey questions include measures of self-rated health, and self-reported height and weight, knowledge and experience using PBSP, physical activity, bicycle helmet use and history of collisions and injuries while cycling, socio-demographic questions, and home/workplace locations. Respondents could complete questionnaires in English, French, and Spanish. Two weights will be applied to the data: inverse probability of selection and post-stratification on age and sex.

A triple difference analysis will be used. This approach includes in the models, time, exposure, and treatment group, and interaction terms between these variables to estimate changes across time, between exposure groups and between cities.

Discussion: There are scientific and practical challenges in evaluating PBSP. Methodological challenges included: appropriate sample recruitment, exchangeability of treatment and control groups, controlling unmeasured confounding, and specifying exposure. Practical challenges arise in the evaluation of environmental interventions such as a PBSP: one of the companies involved filed for bankruptcy, a Hurricane devastated New York City, and one PBSP was not implemented. Overall, this protocol provides methodological and practical guidance for researchers wanting to study PBSP impacts on health.
\end{abstract}

Keywords: Natural experiment, Bicycle share program, Population health, Protocol, Evaluation

\footnotetext{
* Correspondence: daniel.fuller@usask.ca

'Department of Community Health and Epidemiology, University of

Saskatchewan, Saskatchewan, Canada

Full list of author information is available at the end of the article
} 


\section{Background}

Public bicycle share programs (PBSP) are a promising environmental intervention that deploy bicycles at docking stations throughout a city or territory [1]. Increasingly popular around the world, PBSP have grown from five programs in Europe in 2000 to an estimated 600,000 bicycles across 636 programs in 49 countries in 2013 [2]. Despite rapid expansion, a recent review suggests that the impacts of these programs on health are poorly understood [3]. Preliminary studies of PBSP show that implementation is associated with increased levels of physical activity [4] without increased risk of collisions between cyclists and motor vehicles [2,5]. Safety features may differ between PBSP and personal bike use. For example PBSP bikes have daytime running lights, wide tires, and gearing that does not facilitate high speed travel $[3,6]$. However, PBSP users are less likely to wear helmets $[4,7]$. There are a number of scientific and practical challenges that have limited rigorous evaluations of PBSP impacts on health.

A first challenge is that studies examining PBSP programs are often case studies conducted in one city. There have been few attempts to generalize results by studying multiple cities simultaneously. Second, many cycling studies do not meet scientific criteria for internal validity, $[8,9]$ because PBSP interventions are generally implemented outside of the research sector. It is difficult for researchers to undertake the necessary steps (i.e., study design, ethics, funding) for evaluation prior to implementation $[10,11]$. As a result, the overall validity, and particularly the internal validity of these studies are often wanting. For example, studies may not include pre-intervention measures or control groups. Finally, few publications provide study protocols describing the study design in detail making replication by independent research groups challenging.

Given the need for more research examining the potential health impacts, both positive and negative, of PBSP and the dearth of published protocols, we present the protocol for the International Bikeshare Impacts on Cycling and Collisions Study (IBICCS). The IBICCS study aims to examine the impact of PBSP on population-levels of cycling and risk of collisions between cyclists and motor vehicles in North America. We also discuss the methodological challenges for future studies examining PBSP health impacts.

\section{Methods}

\section{Design}

A quasi-experimental non-equivalent groups design was used [12]. This design is similar to a pretest-posttest randomized experiment but lacks randomization. Rather, intact groups (in this case, populations living in different cities) are used as treatment and control groups. The primary advantages of the non-equivalent groups design over past research are the pre-post measurement and inclusion of comparison groups [13,14]. The pre-post measurement controls for potential reverse causality and factors that do not change within cities over time. Comparison groups allow for a plausible contrast to be made between cities. In randomized designs, it is assumed that treatment and control groups are exchangeable on all measured and unmeasured factors, on average, except the intervention. Because we used propensity score matching (discussed below), we assumed that cities were exchangeable, on average, on measured factors included in the propensity score analysis. Ethical approval was granted by the "Centre de Recherche du Centre Hospitalier de l'Université de Montréal."

\section{Intervention and control cities}

Intervention cities were Montreal, Toronto, Boston, New York, and Vancouver. Intervention cities either had an existing PBSP (Montreal, Toronto \& Boston) or a planned implementation in Spring 2012 (New York) or 2013 (Vancouver). To identify control cities, we used propensity score matching with replacement based on total population, population density, cycling rates, and average yearly temperature from the 60 largest cities in the United States and Canada based on data from the 2010 US census, 2008 American Community Survey, 2006 Canadian Census, Environment Canada, and US National Weather Service. One to one propensity score matching identified intervention and control cities similar on observable characteristics [15]. Matching with replacement ensured the best match, which is of critical importance for causal inference given the small number and variability between cities. Control cities were Chicago (comparison for New York, Montreal, Toronto), Detroit (for Boston), and Philadelphia (for Vancouver). STATA's "psmatch2" command was used to conduct the matching analysis [16].

\section{Sampling plan}

The study used three repeated, cross-sectional surveys in intervention and control cities in Fall 2012 (baseline), 2013 (year 1), and 2014 (year 2). We conducted repeated, cross sectional surveys rather than a longitudinal design (i.e., repeated measures of individuals across time) because the interest is in outcomes at the population level and to estimate population prevalence of PBSP use across time. Surveys were intended to be administered starting on November 1 of each year with 3-4 weeks anticipated for data collection. Prior to the baseline survey Hurricane Sandy struck New York between October 26 and October 29, 2012. Data collection was delayed for the baseline survey until November 12, 2012. There is discrepancy between data collection periods between the first (November 
12 to December 12, 2012) and second (November 1 to November 22, 2013) surveys.

The sampling frame for the study was individuals aged $18+$ years residing in and around areas where PBSP stations are (or would) be implemented during the study period. Forward Sortation Areas (FSA, Canada) and ZIP codes (USA) defined the sampling areas in each city.

A polling firm drew the sample from a non-probabilistic online panel survey operated by a private company. Online panel surveys are constructed for the purpose of participating in future surveys, typically for a monetary incentive. Anyone may choose to become a panel member and must provide verifiable information about their personal characteristics (e.g., age, sex, place of residence, education and income category) [17]. Respondents provided informed consent online by clicking a required check box. Respondents were offered a small financial incentive (\$1-2 or equivalent points at retailers) for survey completion.

A proportional sampling approach was used in each city. The sampling plan called for a total of 12,000 respondents to be sampled. In each of the 8 cities 1000 respondents were sampled with an additional 4000 respondents to be sample based on the total population of the city. Table 1 shows the total population, sampling frame population $(\mathrm{N})$, and the targeted sample size $(n)$ for each city.

\section{Questionnaire}

The questionnaire included 5 sections (see Additional file 1); health status, including self-rated health, and selfreported height and weight; knowledge and experience using PBSP; physical activity, using the International
Physical Activity [18] and the US Behavioral Risk Factor Surveillance System questionnaires [19]; bicycle helmet use and history of collisions and injuries while cycling; and standard socio-demographic questions from the Statistics Canada and US Census questionnaires; and information about home and workplace locations. Respondents could complete questionnaires in English, French, and Spanish. Questionnaires were developed by the research team in English and French, and translated to Spanish.

\section{Quantifying exposure}

Exposure to the PBSP for intervention and control cities will be quantified two ways. In control cities we will generate a hypothetical bicycle share program. This will be done based on the criteria of the US Department of Transportation (USDOT), namely, deployed in areas of high population and job density and public transportation connectivity, no more than 500 meters apart, and in locations that are clearly visible [20]. The cities are matched on population density and other characteristics. Within cities PBSP are implemented where population and retail density, and cycling rates are higher. Creating hypothetical station locations in control cities will allow a more precise examination of characteristics within cities where PBSP are deployed or would be deployed.

Using actual (intervention cities) or hypothetical (control cities) station locations, exposure will be defined based on the number of stations within a 500 meter road network buffer of a respondent's home, and workplace. An individual's exposure will be defined in 4 categories: i) fully exposed - at least one station in both their home and work buffers; ii) work exposed - at least one station within their work buffer but no stations within their home buffer; iii)

Table 1 Characteristics of intervention and control cities and targeted sampling plan for the International Bikeshare Impacts on Cycling and Collisions Study (IBICCS), 2012-2014

\begin{tabular}{|c|c|c|c|c|c|c|c|c|}
\hline & \multicolumn{8}{|c|}{ City } \\
\hline & \multicolumn{5}{|c|}{ Intervention } & \multicolumn{3}{|c|}{ Control } \\
\hline & Montreal $^{+}$ & Toronto $^{+}$ & Vancouver $^{+}$ & New York & Boston* & Chicago & Detroit $^{\sim}$ & Philadelphia \\
\hline Population 2012 & $3,917,900$ & $5,841,100$ & $2,426,200$ & $8,336,697$ & 802,065 & $2,697,843$ & 701,475 & $1,547,607$ \\
\hline Sample frame population (N) & 986,565 & $1,577,685$ & 773,300 & $2,754,792$ & 277,184 & $1,275,196$ & 403,621 & 606,330 \\
\hline Targeted sample (n) & 1458 & 1723 & 1168 & 2136 & 1142 & 1750 & 1198 & 1424 \\
\hline Sampling fraction $\left.\left((\mathrm{n} / \mathrm{N})^{*} 100\right)\right)$ & 0.15 & 0.11 & 0.15 & 0.08 & 0.41 & 0.14 & 0.30 & 0.23 \\
\hline Average yearly temperature & 11.1 & 12.5 & 13.7 & 12.5 & 10.8 & 9.3 & 9.7 & 12.8 \\
\hline $\begin{array}{l}\text { Cycling as usual mode of } \\
\text { transportation to work \% }\end{array}$ & 1.6 & 1.0 & 1.7 & 0.8 & 1.4 & 1.3 & 0.3 & 1.8 \\
\hline Population density (square Km) & 854 & 866 & 736 & 10,194 & 4,697 & 4,923 & 2,647 & 4,337 \\
\hline FSA ZIP number & 56 & 70 & 35 & 85 & 42 & 65 & 18 & 19 \\
\hline
\end{tabular}

Notes.

*Includes the populations of Boston, Cambridge and Brookline, Massachusetts.

${ }^{+}$Statistics Canada Census Metropolitan areas.

(http://www.statcan.gc.ca/tables-tableaux/sum-som/l01/cst01/demo05a-eng.htm).

$\sim$ Incorporated Places and Minor Civil Divisions Datasets.

(http://www.census.gov/popest/data/cities/totals/2012/SUB-EST2012.html). 
home exposed - at least one station within their home buffer but no stations within their work buffer; and iv) non exposed - no stations at home and work.

\section{Weighting}

Two weights will be applied to the data: inverse probability of selection and post-stratification on age and sex. Inverse probability of selection weights correct for unequal sampling fractions as not everyone is equally likely to be sampled in each city and area [21]. Poststratification weights on age and sex use valid surveys (census) to adjust the sample characteristics to represent the best estimate of the population [22]. Given that the online panel survey is non-probabilistic using these weights is recommended to reduce sampling bias [17].

\section{Analysis plan}

The proposed data analysis is drawn from techniques which approximate randomized controlled trials in quasi-experiments [23]. A triple difference analysis will be used [24]. This approach includes in the models, time (baseline, year 1, and year 2), exposure (4

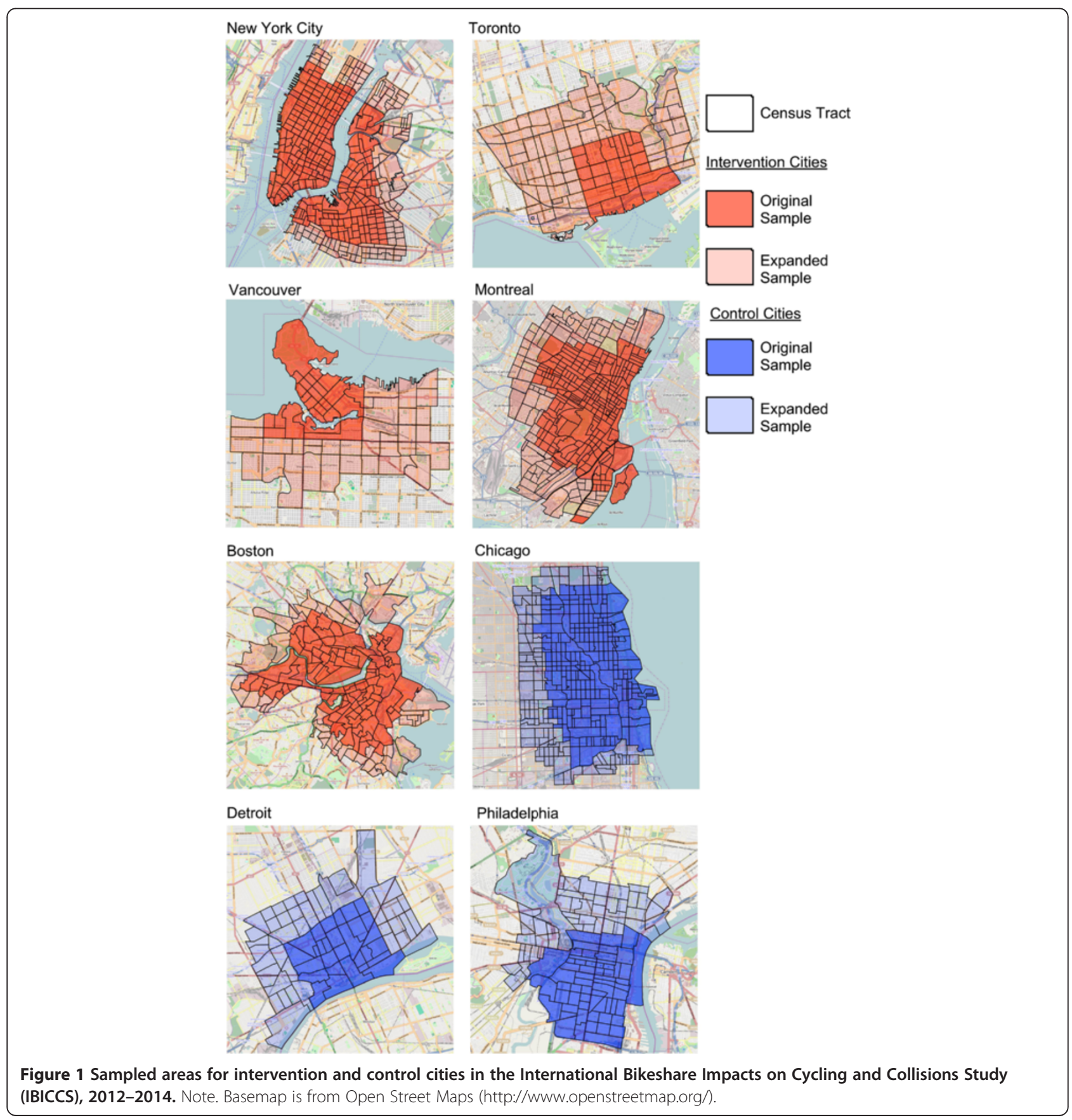


categories), and treatment (intervention and control), and interaction terms between these variables to estimate changes across time, between exposure groups and between cities [14,25]. We will estimate PBSP impacts on cycling, physical activity, and collisions, across time, between exposed and unexposed, and between cities. We will be able to examine the overall impact of PBSP on health and the specific impact in each city.

\section{Discussion}

\section{Treatment/control groups}

A particular challenge for this study is the rapid expansion of PBSP in North America. In June 2013 Chicago, a planned control city, launched the PBSP Divvy (http://divvybikes.com/) with 750 bikes at 75 stations. In Fall 2014, Philadelphia, a planned control city, will launch a PBSP (http://www.phila.gov/bikeshare/Pages/ default.aspx). Vancouver, which had a planned implementation in 2013, was delayed and may not launch during the study period. Despite our efforts to identify intervention and control groups similar on observable characteristics, new implementations and delays of programs mean that by the time data is collected cities may have switched from intervention to control and our exchangeability assumptions will no longer be plausible.

\section{Between country differences}

The international nature of the study introduces challenges. In particular, differences between administrative boundaries used for sampling and defining exposure (FSA vs. ZIP Code vs. Census Tract) may lead to potential bias [26]. The average population of a FSA was 20,463, compared with 30,000 for ZIP codes. Canadian census tracts include 2,500 - 8,000 persons, whereas US census tracts include $1,200-8,000$ people, and an optimum size of 4,000 people. As a result of these geographic differences, modifiable area unit problems are of particular concern $[27,28]$.

\section{Expanded data collection areas}

During the pre-implementation data collection period, we had planned to recruit from a specific set of FSA and ZIP codes. These areas did not generate a sufficiently large sample. After up to 2 reminder emails, we expanded data collection areas on November 30, 2012 to include additional geographic areas. Figure 1 shows the geographic areas added.

\section{Bankruptcy BIXI Montreal}

On January 21 2014, the Montreal-based PBSP filed for bankruptcy protection [29]. This announcement has implications for the study as the Montreal company is an operator or supplier for many PBSP in North America. Although media coverage in New York [30], Vancouver
[31], and Chicago [32] suggest that bankruptcy should not affect operations, its ramifications on implementation, impact, and public perception remain an unknown.

\section{Data sharing}

This project will involve data from several thousand respondents including information on individual health, socio-economic, and environmental exposure data. The project will involve sharing de-identified data with partners from each city and allow for comparisons between cities and local case studies to inform policies around PBSP.

\section{Conclusion}

By introducing the study protocol we hope to stimulate other research groups to replicate and extend the design to ensure comparability between studies, and more valid and generalizable conclusions about the health impacts of implementing PBSP.

\section{Additional file}

Additional file 1: Appendix.

Competing interests

The authors declare that they have no competing interests.

Authors' contributions

DF, LG, and A-SD conceived of the study. All authors participated in the design of the study. DF performed the statistical analysis and drafted the manuscript. All authors read and approved the final manuscript.

\section{Acknowledgements}

The IBICCS team is:

Daniel Fuller, University of Saskatchewan

Lise Gauvin, Université de Montréal

Anne-Sophie Dubé, Université de Montréal

Meghan Winters, Simon Fraser University

Maggie Veatch, New York City Department of Health and Mental Hygiene

Philip Noyes, New York City Department of Health and Mental Hygiene

Kay Teschke, University of British Columbia

Elizabeth T. Russo, Boston Public Health Commission

Andi Camden, Toronto Public Health

Monica Campbell, Toronto Public Health

Carol Mee, Toronto Public Health

Steven Marc Friedman, University of Toronto

This study was funded by the Canadian Institutes of Health Research

Population Health Intervention Research Grant \# ${ }^{271192}$.

\section{Author details}

${ }^{1}$ Department of Community Health and Epidemiology, University of

Saskatchewan, Saskatchewan, Canada. ${ }^{2}$ Research Centre CHUM, Université de Montréal, Montréal, Canada. ${ }^{3}$ Département de médecine sociale et préventive, École de santé publique, Université de Montréal, Montréal, Canada. ${ }^{4}$ Direction de santé publique de l'Agence de la santé et des services sociaux de Montréal, Montréal, Canada. ${ }^{5}$ Faculty of Health Sciences, Simon Fraser University, Burnaby, Canada. ${ }^{6}$ School of Population and Public Health, University of British Columbia, Vancouver, Canada. ${ }^{7}$ Boston Public Health Commission, Boston, Massachusetts, USA. ${ }^{8}$ Healthy Public Policy, Toronto Public Health, Toronto, Canada. ${ }^{9}$ Emergency Medicine, Toronto University Health Network, Toronto, Canada. ${ }^{10}$ Faculty of Medicine, University of Toronto, Toronto, Canada.

Received: 19 August 2014 Accepted: 15 October 2014

Published: 25 October 2014 


\section{References}

1. Shaheen SA, Guzman S, Zhang H: Bikesharing in Europe, the Americas, and Asia. J Transp Res Board 2010, 2143:159-167.

2. Bike sharing World Map. [http://www.bikesharingworld.com]

3. Fishman E, Washington S, Haworth N: Bike share: a synthesis of the literature. Transp Rev 2013, 33:148-165.

4. Fuller D, Gauvin L, Kestens Y, Daniel M, Fournier M, Morency P, Drouin L: Impact evaluation of a public bicycle share program on cycling: a case example of BIXI in Montreal, Quebec. Am J Public Health 2013, 103:e1-e8.

5. Fuller D, Gauvin L, Morency P, Kestens Y, Drouin L: The impact of implementing a public bicycle share program on the likelihood of collisions and near misses in Montreal, Canada. Prev Med 2013, 57:920-924.

6. Madsen JCO, Andersen T, Lahrmann HS: Accident Analysis and Prevention. Accid Anal Prev 2013, 50:820-829.

7. Bonyun M, Camden A, Macarthur C, Howard A: Helmet use in BIXI cyclists in Toronto, Canada: an observational study. BMJ Open 2012, 2:e001049-e001049.

8. Yang L, Sahlqvist S, McMinn A, Griffin SJ, Ogilvie D: Interventions to promote cycling: systematic review. BMJ 2010, 341:c5293-c5293.

9. Pucher J, Dill J, Handy S: Infrastructure, programs, and policies to increase bicycling: An international review. Prev Med 2010, 50:S106-S125.

10. Petticrew M, Cummins S, Ferrell C, Findlay A, Higgins C, Hoyd C, Kearnsd A Sparks L: Natural experiments an underused tool for public health. Public Health 2005, 119:751.

11. Craig P, Cooper C, Gunnell D, Haw S, Lawson K, Macintyre S, Ogilvie D, Petticrew M, Reeves B, Sutton M, Thompson S: Using natural experiments to evaluate population health interventions: new Medical Research Council guidance. J Epidemiol Community Health 2012, 66:1182-1186.

12. Shadish WR, Cook TD: The renaissance of field experimentation in evaluating interventions. Annu Rev Psychol 2009, 60:607-629.

13. Bonell CP, Hargreaves J, Cousens S, Ross D, Hayes R, Petticrew M, Kirkwood BR: Alternatives to randomisation in the evaluation of public health interventions: design challenges and solutions. J Epidemiol Community Health 2011, 65:582-587.

14. Cousens S, Hargreaves J, Bonell C, Armstrong B, Thomas J, Kirkwood BR, Hayes R: Alternatives to randomisation in the evaluation of public-health interventions: statistical analysis and causal inference. J Epidemiol Community Health 2011, 65:576-581.

15. Harder VS, Stuart EA, Anthony JC: Propensity score techniques and the assessment of measured covariate balance to test causal associations in psychological research. Psychol Methods 2010, 15:234-249.

16. Leuven E, Sianesi B: PSMATCH2: Stata Module to Perform Full Mahalanobis and Propensity Score Matching, Common Support Graphing, and Covariate Imbalance Testing. 4th edition. 2003 [https://ideas.repec.org/c/boc/bocode/ s432001.html]

17. American Association for Public Opinion Research: Report on Online Panels: American Association for Public Opinion Research; 2010:1-81 [https://www. aapor.org/AAPOR_Releases_Report_on_Online_Survey_Panels1.htm]

18. Craig CL, Marshall AL, Sjöström M, Bauman AE, Booth ML, Ainsworth BE, Pratt M, Ekelund U, Yngve A, Sallis JF, Oja P: International physical activity questionnaire: 12-country reliability and validity. Med Sci Sports Exerc 2003, 35:1381-1395.

19. Yore MM, Ham SA, Ainsworth BE, Kruger J, Reis JP, Kohl HWI, MACERA CA: Reliability and validity of the instrument used in BRFSS to assess physical activity. Med Sci Sports Exerc 2007, 39:1267-1274.

20. USDOT Federal Highway Administration: Bike Sharing in the United States: State of the Practive and Guide to Implementation; 2012:1-68 [http://www. pedbikeinfo.org/pdf/Programs_Promote_bikeshareintheus.pdf]

21. Seaman SR, White IR: Review of inverse probability weighting for dealing with missing data. Stat Methods Med Res 2013, 22:278-295.

22. Brick J, Kalton G: Handling missing data in survey research. Stat Methods Med Res 1996, 5:215-238.

23. Rubin DB: Estimating causal effects of treatments in randomized and non-randomized studies. J Educ Psychol 1974, 66:688-701.

24. Meyer BD: Natural and quasi-experiments in Economics. J Bus Econ Stat 1995, 13:151-161.

25. Rickles D: Causality in complex interventions. Med Health Care Philos 2008, 12:77-90.

26. Krieger N, Waterman P, Chen JT, Soobader M-J, Subramanian SV, Carson R: Zip code caveat: bias due to spatiotemporal mismatches between zip codes and us census-defined geographic areas - the public health disparities geocoding project. Am J Public Health 2002, 92:1100.
27. Openshaw S: The Modifiable Areal Unit Problem. Norwich, England: GeoBooks; 1984

28. Clark A, Scott D: Understanding the impact of the modifiable areal unit problem on the relationship between active travel and the built environment. Urban Stud 2013, 51:284-299.

29. Despite bankruptcy protection, Coderre sees Bixi rolling in spring [http://montrealgazette.com/news/local-news/bixi-damage-control-begins-butmany-questions-remain]

30. CitiBike Manufacturer Files For Bankruptcy. [http://observer.com/2014/01/ officials-doing-their-darndest-to-keep-bankrupt-citibike-manufacturer-spinning/]

31. Vancouver bike share to proceed, despite Bixi bankruptcy. [http://www. theglobeandmail.com/news/british-columbia/wheels-havent-fallen-offvancouvers-bike-share-ambitions/article16509917/]

32. Divvy Bikes Supplier, Bixi, Files For Bankruptcy; City Officials Say It Won't Affect Expansion Plans. [http://www.huffingtonpost.com/2014/01/21/bixibikes-bankruptcy_n_4637847.html]

doi:10.1186/1471-2458-14-1103

Cite this article as: Fuller et al: Evaluating the impact of environmental interventions across 2 countries: the International Bikeshare Impacts on Cycling and Collisions Study (IBICCS) Study protocol. BMC Public Health 2014 14:1103.

\section{Submit your next manuscript to BioMed Central and take full advantage of:}

- Convenient online submission

- Thorough peer review

- No space constraints or color figure charges

- Immediate publication on acceptance

- Inclusion in PubMed, CAS, Scopus and Google Scholar

- Research which is freely available for redistribution 